\title{
Effect of electromagnetic stirring on metallurgical quality of GCr15 electroslag ingot
}

\author{
Xiao-fang Shi', Tao $\mathrm{Xu}^{2}$, and ${ }^{*} \mathrm{Li}-z h o n g$ Chang ${ }^{1}$ \\ 1. School of Metallurgy Engineering, Anhui University of Technology, Ma'anshan 243002, Anhui, China \\ 2. Anhui Fukai Special Material Co., Ltd., Jixi 245300, Anhui, China
}

\begin{abstract}
To further improve the metallurgical quality of electroslag remelting, remove the large inclusions in electroslag ingot and refine the solidification structure of electroslag ingot, an electroslag remelting furnace with electromagnetic stirring was designed, and the influence of different magnetic induction intensities on metallurgical quality of GCr15 electroslag ingot was studied. Inclusions with different sizes and types were analyzed by an ASPEX scanning electron microscope, and the morphology and composition of inclusions were further observed by a JSM-6510LV scanning electron microscope. The distribution of alloying elements on the cross section of electroslag ingot was analyzed by original position analysis (OPA). The results show that whether or not electromagnetic stirring is used, the inclusions in electroslag ingot are mainly composed of $\mathrm{Al}_{2} \mathrm{O}_{3}$, $\mathrm{MnS}, \mathrm{MnS}$-oxide and other oxides, among which $\mathrm{Al}_{2} \mathrm{O}_{3}$ is the most. Compared with an electroslag ingot without electromagnetic stirring, the number of inclusions decreases considerably, and the proportion of small inclusions increases while the proportion of large inclusions decreases when the electromagnetic stirring with remelting current of $1.1 \mathrm{kA}$ and magnetic induction intensity of $62 \mathrm{Gs}$ is applied. However, excessive electromagnetic force will cause the number and diameter of inclusions to increase again. Electromagnetic stirring has different effects on the segregation of different elements. Under the experimental conditions, the weak electromagnetic force with $1.1 \mathrm{kA}$ and magnetic induction intensity of $108 \mathrm{Gs}$ has little effect on the segregation of $\mathrm{C}$, but decreases the segregation of $\mathrm{P}$, and the excessive electromagnetic force aggravates the segregation of alloy elements.
\end{abstract}

Keywords: electroslag remelting; electromagnetic stirring; inclusion; solidification; segregation; GCr15 bearing steel
CLC numbers: TG142.72
Document code: A
Article ID: 1672-6421 2022 01-046-09

\section{Introduction}

As a special metallurgical method, electroslag remelting (ESR) technology has been widely used. The most remarkable advantage for ESR is that it can improve the purity and solidification quality of metal. In the traditional metallurgical process, molten steel is treated in lined vessels from smelting to casting. The molten steel will inevitably be polluted by the lining, such as the spalling of refractory, and the involvement of mold flux ${ }^{[1]}$. These accidental and irregular large inclusions have a very adverse effect on the properties of metals. In the ESR process, the contact area between slag and molten

\section{*Li-zhong Chang}

Male, born in 1977, Ph.D, Professor. His research interests mainly focus on electroslag metallurgy and inclusion control in steel. To date, he has published more than 50 academic papers in international and domestic journals. He has presided over the completion of more than 20 projects, including projects supported by the National Natural Science Foundation of China.

E-mail: clz1997@163.com

Received: 2021-05-24; Accepted: 2021-12-24 metal is 20,000 times higher than that in an ordinary refining process, which makes the large inclusions to be fully absorbed by slag ${ }^{[2]}$. Therefore, the inclusions in electroslag ingots are fine and dispersed. Zhou et al. ${ }^{[3]}$ studied the change of inclusion during ESR of bearing steel, and found the original inclusions in a consumable electrode can be basically removed or dissolved, and the inclusions in an ESR ingot are mainly newly formed in the crystallization process of the molten pool. In addition to inclusions, the solidification quality also has a very important influence on product performance. One of the most important reasons why ESR is widely used is its improvement of the solidification quality of the ingot. After ESR, the secondary dendrite spacing of the ingot decreases, and the distribution of alloying elements is more uniform ${ }^{[4]}$.

Although ESR can improve the solidification quality and purity of the metal, large inclusions are occasionally found in electroslag ingots ${ }^{[5]}$. Although the inclusions are smaller than those produced by the traditional steelmaking process, they still need 
to be further removed for some key materials. The excellent solidification quality of electroslag ingots is based on the formation of a shallow molten pool in the ESR process. However, with the increase of electroslag ingot diameter, the cooling capacity of the core gradually worsens, so the depth of the molten pool gradually increases, which leads to the deterioration of the solidification structure. The metallurgical quality of electroslag ingots should be further improved for some special materials, and many new electroslag technologies, especially electromagnetic stirring, have attracted the attention of metallurgical workers. Murgaš et al. ${ }^{[6]}$ studied the effect of a stable magnetic field on M2 high-speed steel and found that the magnetic field improved the solidification structure of M2 steel. However, Mitchell et al. ${ }^{[7]}$ found that the initiation of electromagnetic stirring with alternating current during electroslag remelting was accompanied by a thin strip of segregated material and favored the formation of spot segregation. Zhong et al. ${ }^{[8]}$ studied the effect of a transverse static magnetic field on microstructure and properties of GCr15 bearing steel in the electroslag continuous casting process, and found that the presence of a static magnetic field was beneficial for microstructure refinement as well as inclusion and harmful elements removal. Guo et al. ${ }^{[9-11]}$ studied the change of inclusions during the electroslag remelting process assisted by a static magnetic field, and found the kinetic conditions for inclusion removal were enhanced, leading to a decrease in the number and size of inclusions.

To further study the effect of electromagnetic stirring on electroslag remelting, a new ESR furnace with a stable axial magnetic field was designed in the present study, and the effects of different electromagnetic forces on the remelting efficiency, removal of large inclusions, and solidification structure of GCr15 bearing steel were analyzed in detail.

\section{Experimental equipment and schemes}

Figure 1 shows the schematic diagram of the electroslag furnace with electromagnetic stirring and remelting process. A DC current flows into the spiral coil around the mold to generate a stable axial magnetic field. The maximum magnetic induction intensity in the core of the mold could reach 230 Gs in the unloaded mold. The diameters of the mold and metal consumable electrode were $100 \mathrm{~mm}$ and $55 \mathrm{~mm}$, respectively.

(a)
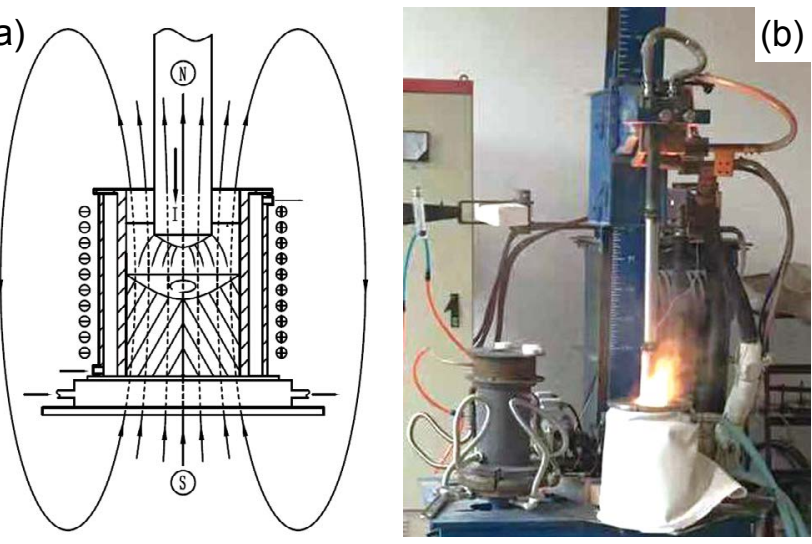

Fig. 1: Experimental equipment: (a) schematic diagram of ESR with electromagnetic stirring; (b) remelting process

The material used in this research was GCr15 bearing steel, and its composition is as follows (wt.\%): C: 0.95-1.05, Mn: 0.25-0.45, Si: 0.15-0.35, Cr: 1.40-1.65, AlS: 0.015-0.025, $\mathrm{P} \leq 0.025, \mathrm{~S} \leq 0.025$. The slag used during the ESR process was $30 \% \mathrm{Al}_{2} \mathrm{O}_{3}+70 \% \mathrm{CaF}_{2}$.

The experimental schemes are shown in Table 1. Before ESR, the scale of the electrode surface was removed by grinding.

Table 1: Experimental schemes

\begin{tabular}{ccccc} 
Scheme No. & $\begin{array}{c}\text { Remelting current } \\
(\mathbf{K A})\end{array}$ & $\begin{array}{c}\text { Remelting voltage } \\
(\mathrm{V})\end{array}$ & $\begin{array}{c}\text { Magnetic induction } \\
\text { intensity (Gs) }\end{array}$ & $\begin{array}{c}\text { Remelting speed } \\
\left(\mathbf{g} \cdot \mathrm{min}^{-1}\right)\end{array}$ \\
\hline 1 & 1.5 & 34 & 0 & 370 \\
2 & 1.1 & 34 & 62 & 370 \\
3 & 1.1 & 34 & 108 & 370 \\
4 & 1.5 & 34 & 62 & 500 \\
5 & 1.5 & 34 & 108 & 500
\end{tabular}

All experiments were carried out in air, and no deoxidizer was added to the slag bath during the ESR process. The diameter and height of electroslag ingots were $95-100 \mathrm{~mm}$ and 190-200 mm, respectively. The weight was $1,200 \mathrm{~g}$.

During the ESR process, the dropping height of electrode in a certain time was counted. The ESR is a process in which the length of the electrode decreases and the height of the electroslag ingot increases. The decrease of electrode and the increase of ingot are in relative motion. So, the calculation method for the melting length of electrode based on the dropping height of the electrode is shown in Eq. (1).

$$
L_{1}=\frac{D^{2}}{D^{2}-\mathrm{d}^{2}} L
$$

where $L_{1}$ : the melting length of electrode in a certain time, mm; $L$ : the dropping height of electrode in a certain time, $\mathrm{mm} ; D$ : the diameter of mold, $\mathrm{mm}$; $d$ : the diameter of electrode, $\mathrm{mm}$. 
According to $d, L_{1}$ and electrode density, the remelting speed $\left(\mathrm{g} \cdot \mathrm{min}^{-1}\right)$ can be calculated.

After ESR, a $15 \mathrm{~mm} \times 15 \mathrm{~mm} \times 15 \mathrm{~mm}$ sample was taken from the center position of the ESR ingot. The distribution of inclusions with different sizes and chemical compositions was analyzed by using an ASPEX scanning electron microscope, and the morphology of inclusions was further observed by using a JSM-65101v scanning electron microscope. The distribution of alloying elements on the cross section of the electroslag ingot was analyzed by using an original position analysis (OPA) apparatus ${ }^{[12]}$.

\section{Results}

\subsection{Composition of inclusions}

Figure 2 shows the variations of inclusions with different compositions in the electroslag ingots with different electrical and magnetic parameters. Under five experimental schemes, the inclusions are mainly composed of $\mathrm{Al}_{2} \mathrm{O}_{3}, \mathrm{MnS}, \mathrm{MnS}$ oxide, and other composite oxides. Among them, the proportion of $\mathrm{Al}_{2} \mathrm{O}_{3}$ is the highest, while the proportion of $\mathrm{MnS}$ is the lowest. The proportion of MnS-oxide composite inclusions and oxide inclusions is similar under certain parameters. Among the five experimental schemes, $\mathrm{Al}_{2} \mathrm{O}_{3}$ has the highest proportion in the ingot prepared by Scheme 1 . However, when the remelting current is $1.5 \mathrm{kA}$, the proportion of $\mathrm{Al}_{2} \mathrm{O}_{3}$ decreases from $78.54 \%$ to $57.4 \%$ as the magnetic induction intensity changes from zero to $62 \mathrm{Gs}$, and then increases to $70.67 \%$ again when the magnetic induction intensity increases to $108 \mathrm{Gs}$. When the remelting current is $1.1 \mathrm{kA}$, the proportion of $\mathrm{Al}_{2} \mathrm{O}_{3}$ slightly decreases from $54.3 \%$ to $50.6 \%$ as the magnetic induction intensity changes from 62 Gs to $108 \mathrm{Gs}$. When the magnetic induction intensity is $62 \mathrm{Gs}$, the proportion of $\mathrm{Al}_{2} \mathrm{O}_{3}$ slightly increases from $54.3 \%$ to $57.4 \%$ as the remelting current increases from $1.1 \mathrm{kA}$ to $1.5 \mathrm{kA}$. When the magnetic induction intensity is $108 \mathrm{Gs}$, the proportion of $\mathrm{Al}_{2} \mathrm{O}_{3}$ significantly increases from $50.6 \%$ to $70.67 \%$ as the remelting current increases from $1.1 \mathrm{kA}$ to $1.5 \mathrm{kA}$. It can be seen from the change of $\mathrm{Al}_{2} \mathrm{O}_{3}$ inclusions that increasing the remelting current or magnetic induction intensity results in the increase of electromagnetic force. A slight increase in electromagnetic force can decrease the proportion of $\mathrm{Al}_{2} \mathrm{O}_{3}$, while too much electromagnetic force weakens the ability to remove $\mathrm{Al}_{2} \mathrm{O}_{3}$ inclusions during ESR.
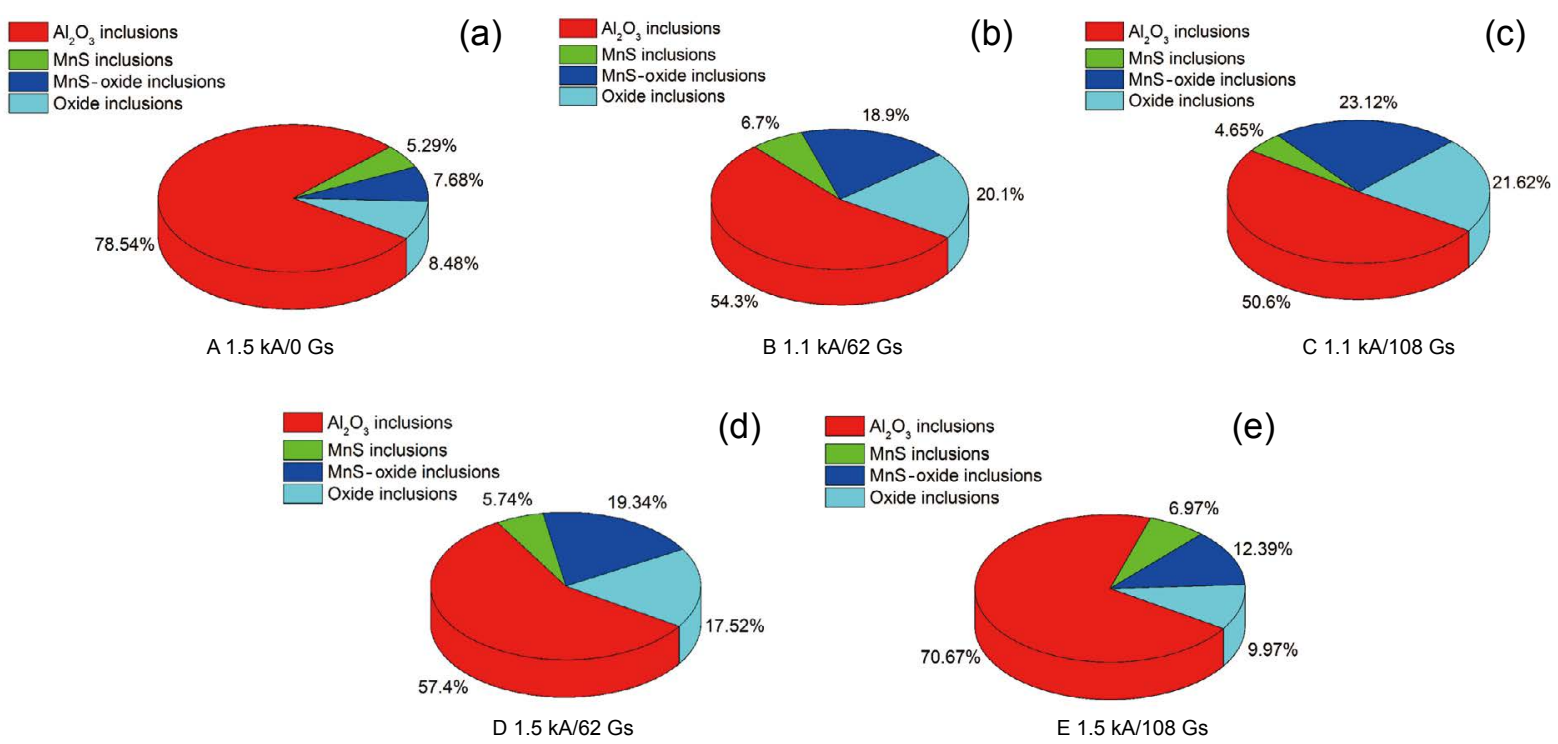

Fig. 2: Proportion of inclusions in electroslag ingots: (a) $1.5 \mathrm{kA} / 0 \mathrm{Gs}$; (b) $1.1 \mathrm{kA} / 62 \mathrm{Gs}$; (c) $1.1 \mathrm{kA} / 108 \mathrm{Gs}$; (d) $1.5 \mathrm{kA} / 62 \mathrm{Gs}$; (e) $1.5 \mathrm{kA} / 108 \mathrm{Gs}$

The morphology and composition distribution of inclusions are shown in Fig. 3. It can be seen that the morphology of $\mathrm{Al}_{2} \mathrm{O}_{3}$ inclusion is irregular and the size is large [Fig. 3(a)], while the morphology of $\mathrm{MnS}$ inclusion is polygonal and the size is small [Fig. 3(b)]. MnS-oxide composite oxide has a doublelayer structure of MnS wrapping oxide [Fig. 3(c)], while other composite oxides inclusions have an irregular shape, dark color and small size [Fig. 3(d)].

\subsection{Effect of electromagnetic stirring on removal of large inclusions}

Figure 4 shows the variation of the number and diameter of inclusions in the electroslag ingot prepared under the same electrical parameters (voltage $34 \mathrm{~V}$, current $1.5 \mathrm{kA}$ ) and different magnetic induction intensity. As shown in Fig. 4(a), there are 1,002 inclusions, and the largest diameter is $15.02 \mu \mathrm{m}$ when the magnetic induction intensity is zero. When the magnetic induction intensity is $62 \mathrm{Gs}$, there are 662 inclusions, and the largest diameter is $13.98 \mu \mathrm{m}$. When the magnetic induction intensity further increases to $108 \mathrm{Gs}$, the electromagnetic stirring force is the greatest in this study, and the number and diameter of inclusions increase again. Figure 4(b) shows that when the magnetic induction intensity increases from zero to $108 \mathrm{Gs}$, the proportion of inclusions with diameters between $3 \mu \mathrm{m}$ and $5 \mu \mathrm{m}$ increases from only $65.2 \%$ to $80.1 \%$ (62 Gs) and $75.1 \%$ (108 Gs), respectively. For the inclusions with a 

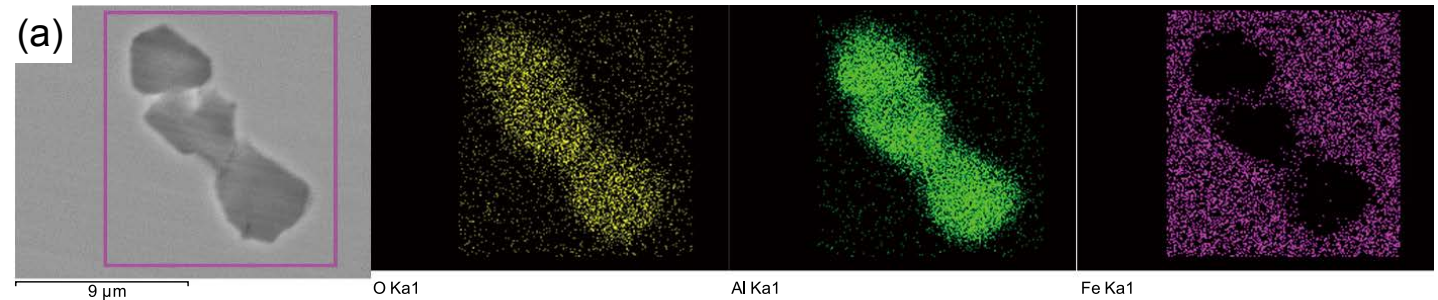

(b)
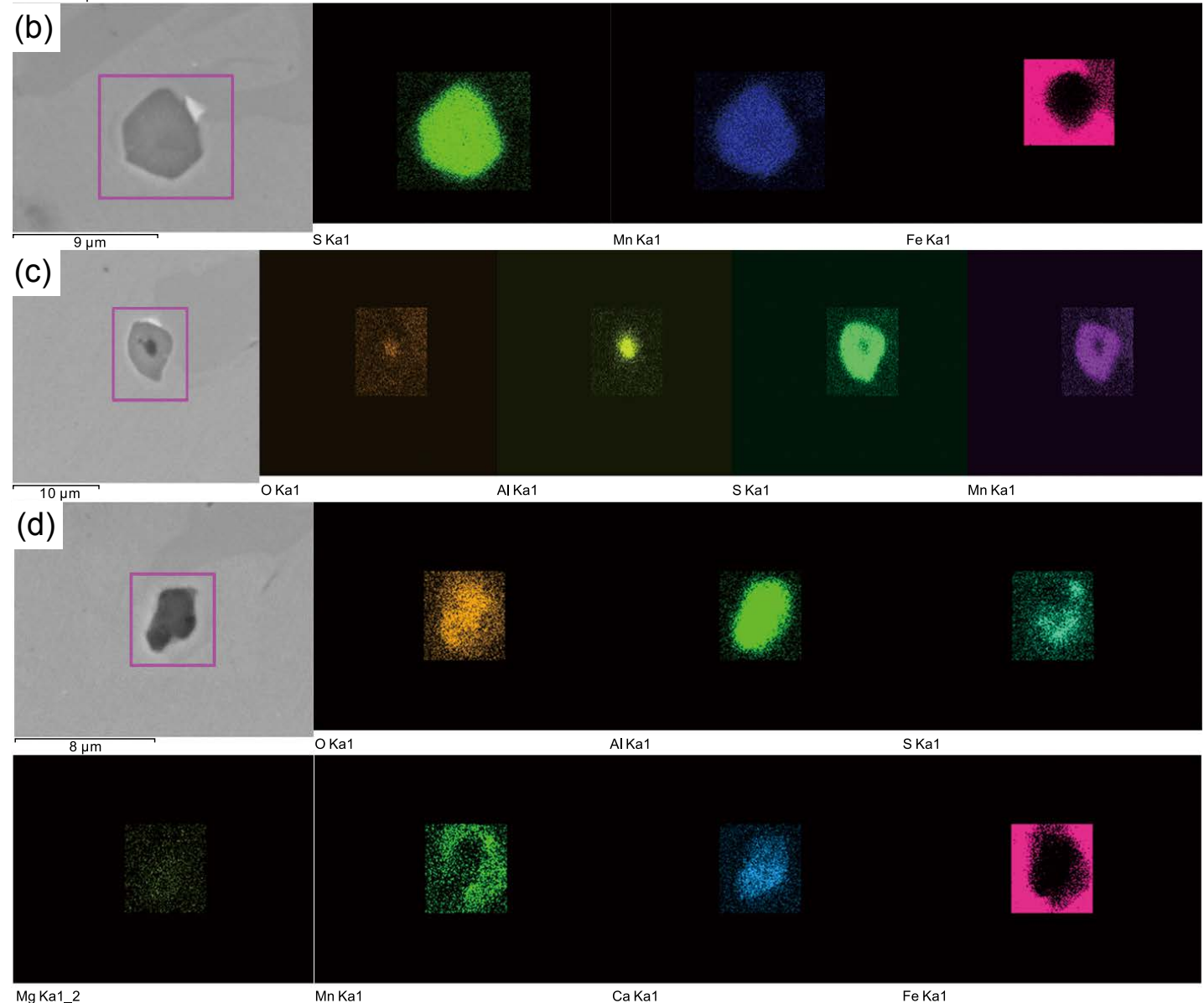

Fig. 3: Morphology and composition of inclusions in ESR ingot: (a) $\mathrm{Al}_{2} \mathrm{O}_{3}$; (b) $\mathrm{MnS}$; (c) MnS-oxide composite inclusions; (d) other composite oxides inclusions

(a)

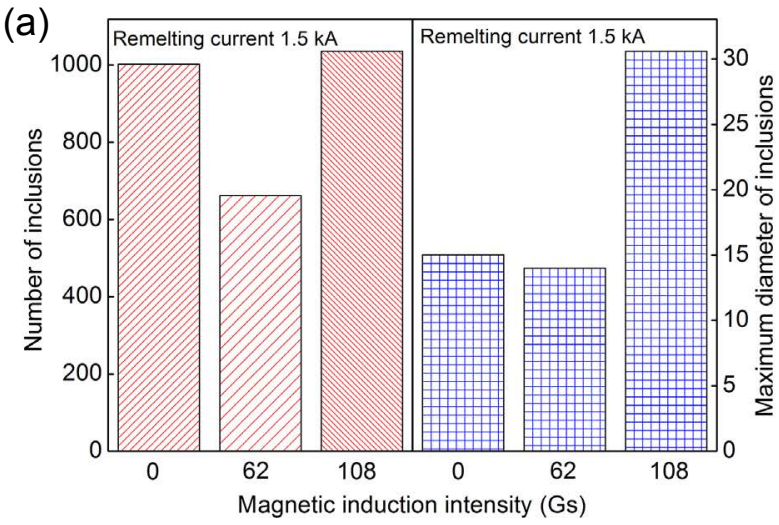

(b)

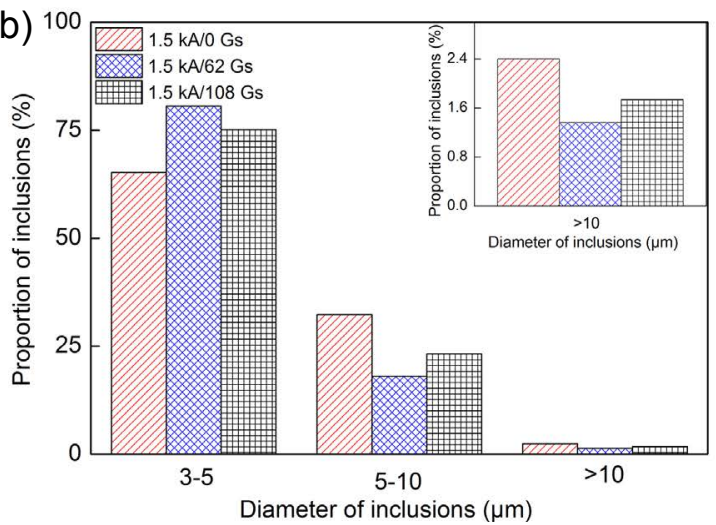

Fig. 4: Effect of magnetic induction intensity on inclusions in ESR ingot: (a) variation of number and diameter of inclusions; (b) distribution of inclusions with different diameters

diameter larger than $10 \mu \mathrm{m}$, the proportion decreases from $2.40 \%$ to $1.36 \%$ when the magnetic induction intensity increases from zero to 62 Gs.

The above analysis shows that when the remelting current is $1.5 \mathrm{kA}$ and the magnetic induction intensity is $62 \mathrm{Gs}$, the number of inclusions is the least, the proportion of small inclusions is the largest, and the proportion of maximum diameter of inclusions is the smallest. However, when the magnetic induction intensity is $108 \mathrm{Gs}$, the number and diameter of inclusions are the largest due to the excessive electromagnetic force. 
Figure 5(a) shows the variation of inclusions in the electroslag ingot when the magnetic induction intensity is $62 \mathrm{Gs}$ and the remelting current is $1.1 \mathrm{kA}$ and $1.5 \mathrm{kA}$. When the remelting current is $1.1 \mathrm{kA}$, there are 582 inclusions in the electroslag ingot, five of which are larger than $10 \mu \mathrm{m}$ in diameter, and the maximum diameter is $14.1 \mu \mathrm{m}$. When the remelting current is $1.5 \mathrm{kA}$, there are 662 inclusions in the electroslag ingot, nine of which are larger than $10 \mu \mathrm{m}$ in diameter, and the maximum diameter is $13.98 \mu \mathrm{m}$. According to the statistical results, the remelting current of 1.1 or $1.5 \mathrm{kA}$ has a slight effect on the inclusions in the electroslag ingot when the magnetic induction density is 62 Gs.

Figure 5(b) shows the change of inclusions when the magnetic induction intensity is $108 \mathrm{Gs}$ and the remelting current is $1.1 \mathrm{kA}$ and $1.5 \mathrm{kA}$. When the current increases from $1.1 \mathrm{kA}$ to $1.5 \mathrm{kA}$, the number of inclusions increases from 669 to 1,036 , and the number of inclusions larger than $10 \mu \mathrm{m}$ increases from 4 to 18 . In addition, the maximum diameter of inclusions increases from $12.12 \mu \mathrm{m}$ to $30.6 \mu \mathrm{m}$.
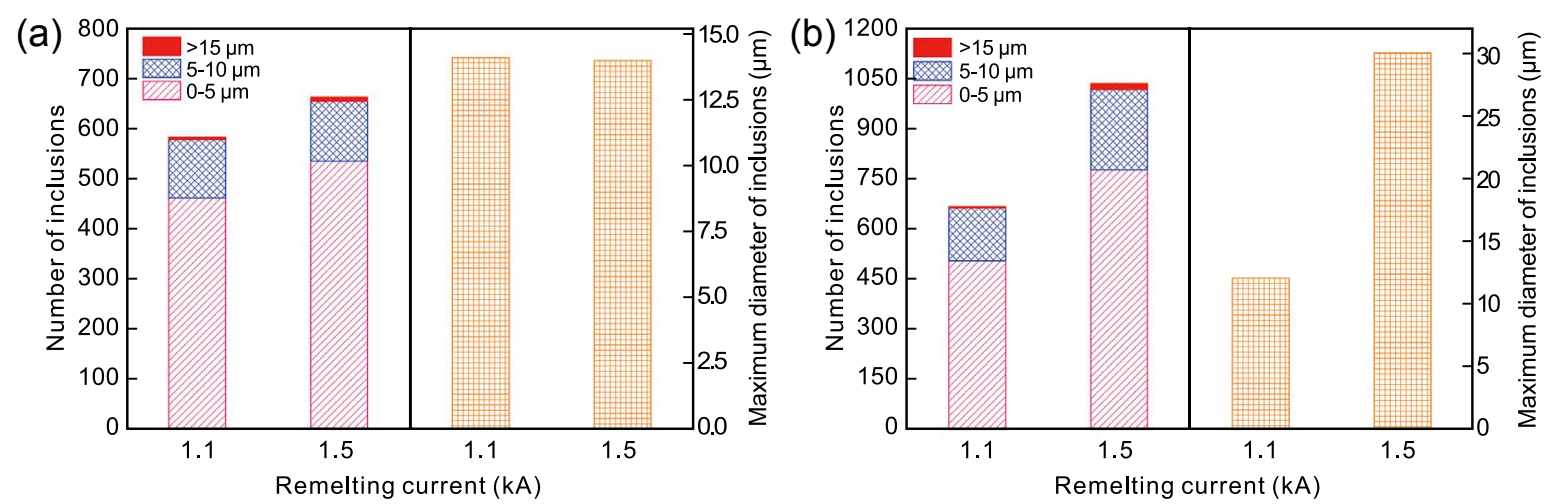

Fig. 5: Effect of remelting current on inclusion distribution in ESR ingot: (a) 62 Gs; (b) 108 Gs

On the basis of the data in Figs. 4 and 5, appropriate electromagnetic stirring in the electroslag process can reduce the number of inclusions and improve the ability of slag to absorb large inclusions. However, improper electromagnetic stirring will deteriorate the purity of the electroslag ingot. Under the experimental conditions, when the remelting current is $1.5 \mathrm{kA}$ and the magnetic induction intensity is $108 \mathrm{Gs}$, the stirring force is the greatest, and the purity of the electroslag ingot is decreased.

\subsection{Effect of electromagnetic stirring on distribution of alloying elements}

In order to evaluate the effect of electromagnetic stirring on the solidification quality in the ESR process, OPA was used to analyze the distribution of alloying elements. Figure 6 shows the effect of different magnetic induction intensities and remelting currents on the distribution of $\mathrm{C}$ content, with different colors indicating different $\mathrm{C}$ contents. Red indicates the highest carbon content, while blue indicates the lowest carbon content. The smoother the 3D surface of $\mathrm{C}$ content, the more uniform the $\mathrm{C}$ content in the ESR ingot.

Figure 6(a) shows that when the remelting current is $1.1 \mathrm{kA}$ and the magnetic induction intensity is $62 \mathrm{Gs}$, the distribution of $\mathrm{C}$ content is relatively uniform, increasing the magnetic induction intensity to $108 \mathrm{Gs}$, the 3D surface of C content becomes uneven, which shows the inhomogeneity of $\mathrm{C}$ content in the ESR ingot. When the remelting current is $1.5 \mathrm{kA}$, there is only a slight change in the distribution of carbon content when the magnetic induction intensity increases from 0 and $62 \mathrm{Gs}$, the distribution of $\mathrm{C}$ content is more uneven when the magnetic induction intensity is $108 \mathrm{Gs}$. When the magnetic induction intensity is $62 \mathrm{Gs}$, the distribution of $\mathrm{C}$ content changes only slightly with the increase of remelting current from 1.1 to $1.5 \mathrm{kA}$. However, when the magnetic induction intensity is $108 \mathrm{Gs}$, the distribution of $\mathrm{C}$ content is obviously uneven with the increase of remelting current from $1.1 \mathrm{kA}$ to $1.5 \mathrm{kA}$.

In order to further quantitatively analyze the influence of electromagnetic stirring on element segregation, the influence of different magnetic induction intensity on the maximum and statistical segregation of $\mathrm{C}$ and $\mathrm{P}$ was studied.

The calculation method of maximum segregation $M$ is shown in Eq. (2):

$$
M=C_{i} / C_{0}
$$

where $C_{i}$ represents the maximum element content of $i$ element in the OPA scanning area; $C_{0}$ represents the average content of $i$ element.

The calculation method of statistical segregation $S$ is shown in Eq. (3):

$$
S=\frac{\sqrt{\sum\left(C_{j}-C_{0}\right)^{2} / N}}{C_{0}}
$$

where $C_{j}$ represents the element content at different positions; $C_{0}$ represents the average element content; $N$ represents the all collected spot number. The larger the statistical segregation, the more serious the element segregation; the smaller the statistical segregation, the more uniform the element distribution. The statistical segregation is zero if there is no segregation.

Figure 7 shows the effect of different magnetic induction intensities on the maximum and statistical segregation of $\mathrm{C}$ and $\mathrm{P}$ elements when the remelting current is $1.5 \mathrm{kA}$. When the magnetic induction intensity increases from zero to $62 \mathrm{Gs}$, 


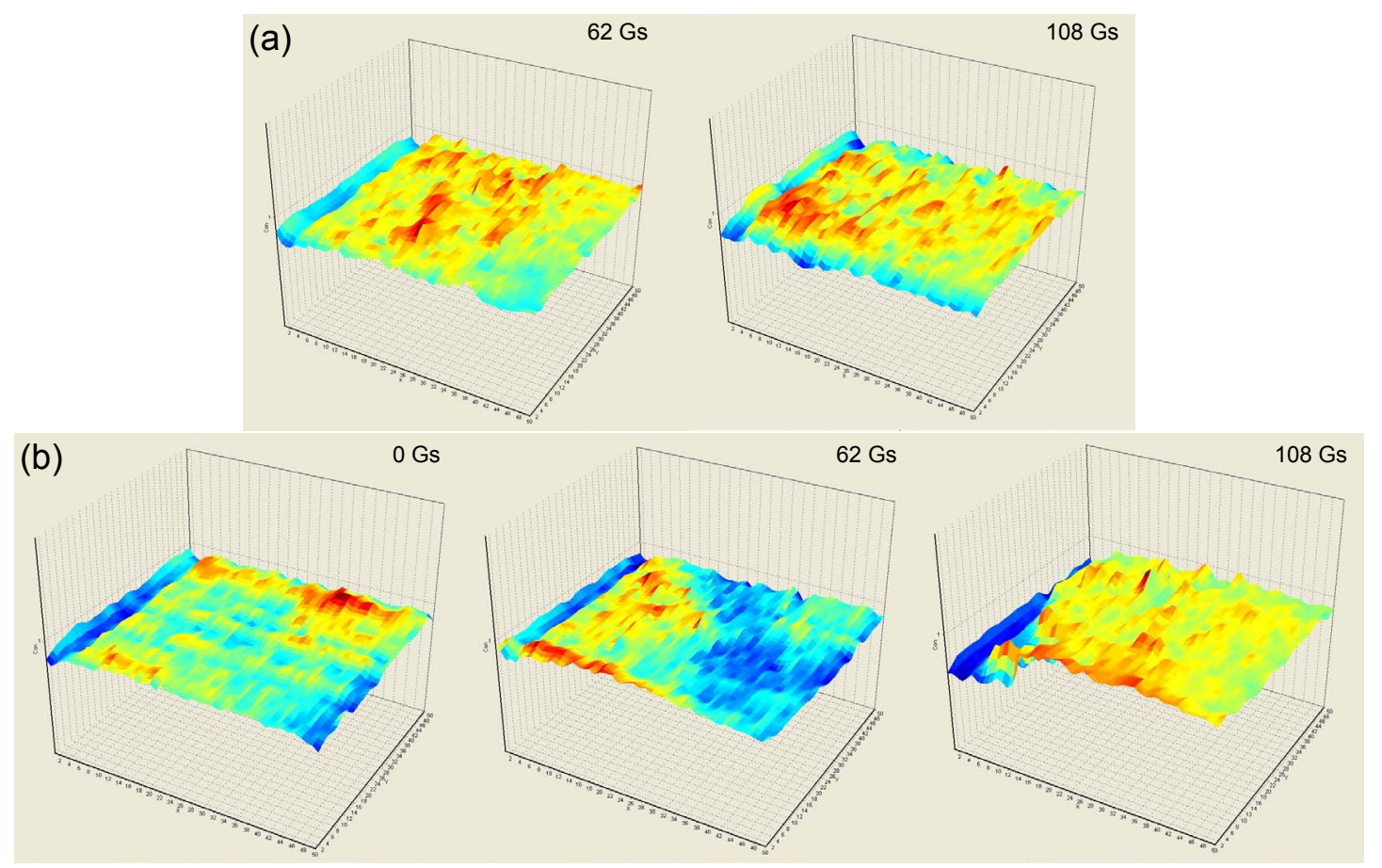

Fig. 6: Effect of magnetic induction intensity and remelting current on $\mathrm{C}$ distribution: (a) remelting current $1.1 \mathrm{kA}$; (b) remelting current $1.5 \mathrm{kA}$

(a)

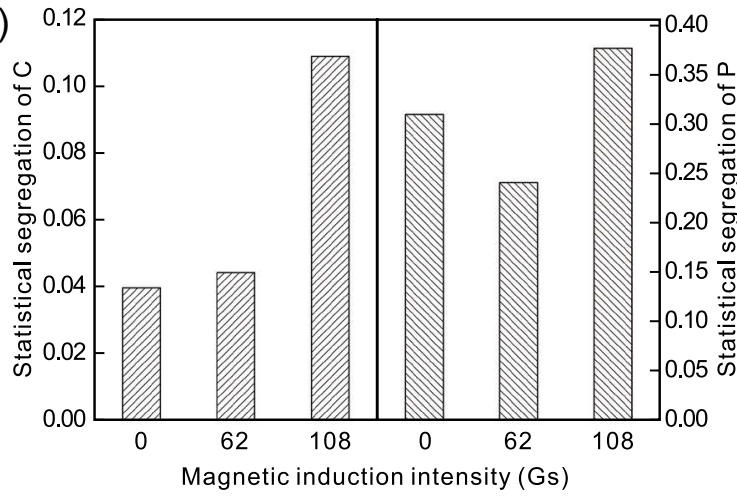

(b)

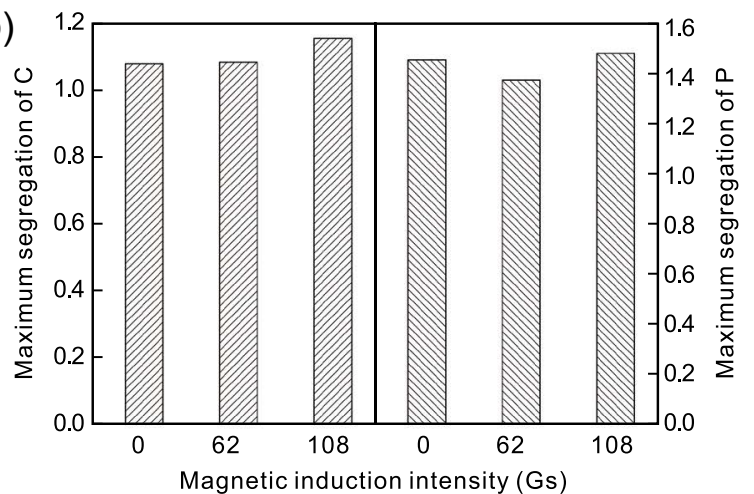

Fig. 7: Effect of different magnetic induction intensities on segregation of $C$ and $P$ (remelting current $1.5 \mathrm{kA}$ ): (a) statistical segregation; (b) maximum segregation

the statistical segregation of $\mathrm{C}$ increases slightly, while that of $\mathrm{P}$ decreases. When the magnetic induction intensity increases to 108 Gs, the statistical segregation of both $\mathrm{C}$ and $\mathrm{P}$ is intensified. The maximum segregation of $\mathrm{C}$ and $\mathrm{P}$ also shows the same trend.
In Fig. 8, when the remelting current is $1.1 \mathrm{kA}$, whether the magnetic induction intensity is 62 or $108 \mathrm{Gs}$, the statistical segregation and maximum segregation of $\mathrm{C}$ and $\mathrm{P}$ do not change much. (a)

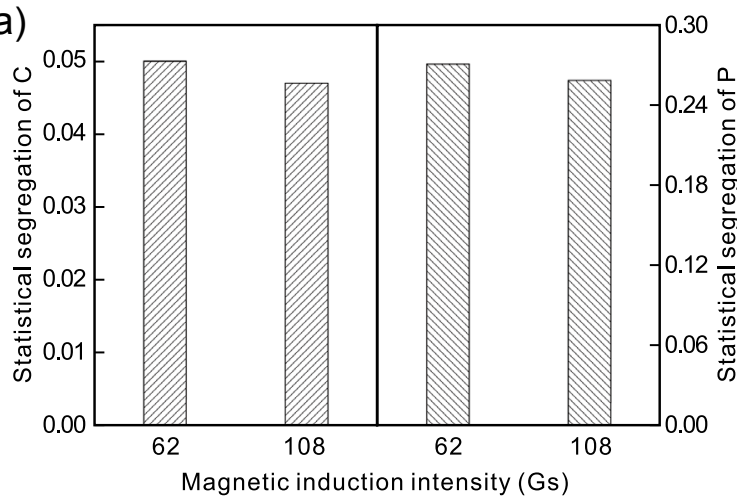

(b)

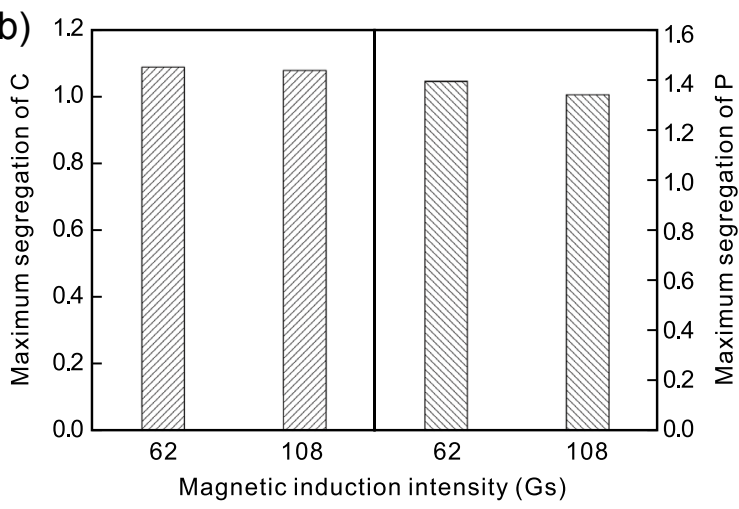

Fig. 8: Effect of different magnetic induction intensity on segregation of $C$ and $P$ (remelting current $1.1 \mathrm{kA}$ ): (a) statistical segregation; (b) maximum segregation 
As can be seen from Figs. 7 and 8, when the magnetic induction intensity is $62 \mathrm{Gs}$, there is a slight decrease in the statistical segregation of $\mathrm{C}$ and $\mathrm{P}$ with the increase of remelting current from $1.1 \mathrm{kA}$ to $1.5 \mathrm{kA}$, while the change of maximum segregation is very small. When the magnetic induction intensity is $108 \mathrm{Gs}$, the statistical segregation of $\mathrm{C}$ and $\mathrm{P}$ increases significantly, and the maximum segregation increases slightly with the increase of remelting current from $1.1 \mathrm{kA}$ to $1.5 \mathrm{kA}$.

The above analysis shows that when the electromagnetic stirring force is great, the solidification structure of the ingot will be deteriorated, and the segregation of both $\mathrm{C}$ and $\mathrm{P}$ will increase. When the electromagnetic force is low, it has little effect on the segregation of $\mathrm{C}$, but improves the segregation of $\mathrm{P}$.

\section{Discussion}

In traditional electromagnetic stirring for continuous casting, a low-frequency current is introduced into the induction coil outside the mold, and then the induction current is generated in the liquid metal. The induction current interacts with the magnetic field to produce electromagnetic force, so as to stir the molten steel ${ }^{[13]}$. In the ESR process, a high density electric current flows between the electrode and a cooled baseplate to heat the slag. As long as a small magnetic field is applied in the mold, a large electromagnetic force can be generated, which can stir the slag pool and metal pool. When electromagnetic stirring is not applied, the metal droplet at the tip of the electrode is subjected to three forces ${ }^{[10]}$ : gravity $(G)$, electromagnetic force $(R)$ and interfacial tension $(P)$ between slag and metal. When the resultant force of the electromagnetic force and gravity exceeds the interfacial tension, droplets melt off the tip of the electrode, fall through the slag, and accumulate in a pool on the baseplate to solidify. When electromagnetic stirring is applied, the liquid metal film and droplet will be stirred because of remelting current passing through the liquid metal film and metal droplet at the end of the electrode, as shown in Fig. 9. When the liquid film at the end of the electrode reaches a certain thickness, it flows downward and converges into metal droplets. Due to the effect of the electromagnetic force, the liquid film accelerates downward movement. That is, it can flow downward and finally converge into droplets even when the film thickness

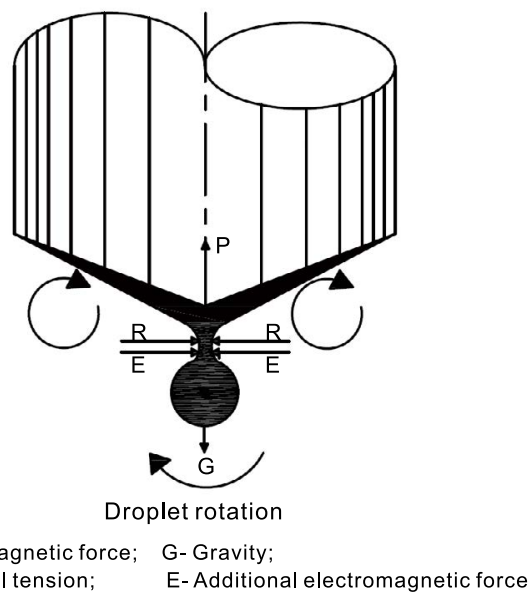

Fig. 9: Droplet dropping process with electromagnetic stirring

is thin. The formation process of the liquid film is also the process of inclusion exposure. The thinner the liquid film, the more likely the inclusion will be exposed and absorbed by the slag. Similarly, there is an additional electromagnetic force $E$ in addition to electromagnetic force $R$ and gravity $G$ under the action of external magnetic field (Fig. 9). When the gravity is low, the size of the droplet is small, and the droplet can be separated from the tip of the electrode. The smaller the droplet size, the larger the contact area between the slag and the metal, and the more easily inclusions are adsorbed by the slag. Therefore, the inclusions in the steel can be removed quickly through reasonable electromagnetic stirring.

Electromagnetic stirring accelerates droplet dropping, which results in the increase of melting speed of metal consumable electrode. This is also confirmed by experiments. When the remelting current is $1.5 \mathrm{kA}$ and the magnetic induction intensity is zero, the remelting speed is $370 \mathrm{~g} \cdot \mathrm{min}^{-1}$. When the magnetic induction intensity increases to 62 or $108 \mathrm{Gs}$, and the melting rate increases to about $500 \mathrm{~g} \cdot \mathrm{min}^{-1}$, as shown in Fig. 10(a). When the remelting current is $1.1 \mathrm{kA}$, the remelting speed is $370 \mathrm{~g} \cdot \mathrm{min}^{-1}$ regardless of the magnetic induction intensity is 62 or $108 \mathrm{Gs}$, as shown in Fig. 10(b).

Figure 11 shows the appearance of ESR ingots with remelting current of $1.5 \mathrm{kA}$ and magnetic induction intensity of 0,62 Gs and $108 \mathrm{Gs}$, respectively. As the remelting power (a)

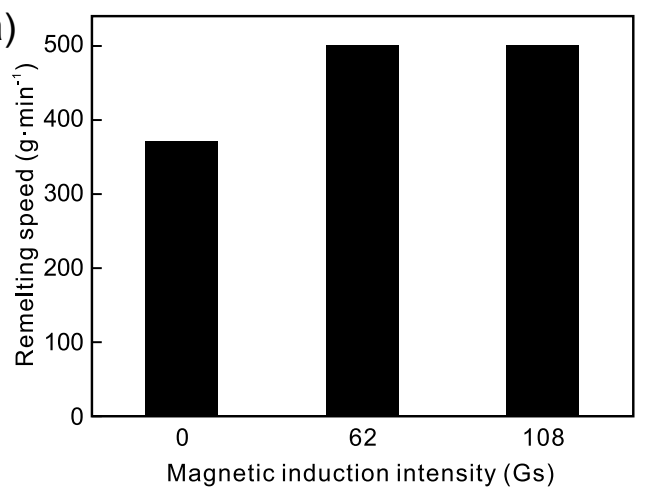

(b)

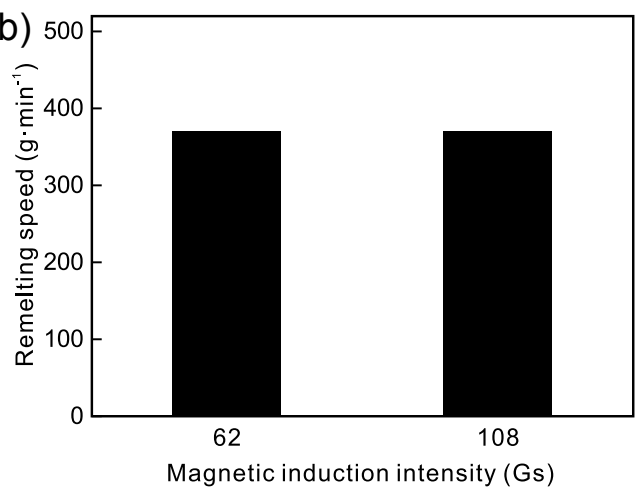

Fig. 10: Effect of remelting current on melting rate: (a) $1.5 \mathrm{kA}$; (b) $1.1 \mathrm{kA}$ 

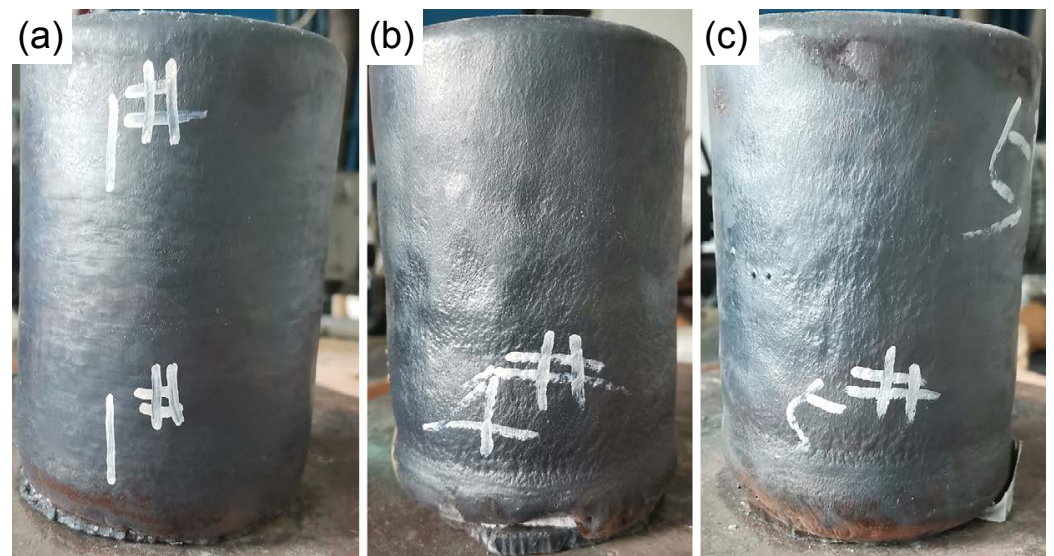

Fig. 11: Appearance of ESR ingot with different process parameters: (a) $34 \mathrm{~V}, 1.5 \mathrm{kA}, 0 \mathrm{Gs}$; (b) $34 \mathrm{~V}, 1.5 \mathrm{kA}, 62 \mathrm{Gs}$; (c) $34 \mathrm{~V}, 1.5 \mathrm{kA}, 108 \mathrm{Gs}$

remains unchanged, the remelting speed increases and the temperature of the slag pool decreases after electromagnetic stirring, resulting in a slightly poor surface quality of ESR ingot.

Electromagnetic stirring also has an important influence on the solidification process of the metal pool. In order to obtain good solidification quality, a shallow metal pool is expected to be formed in the ESR process. The shape of the metal pool is shown in Fig. 12.

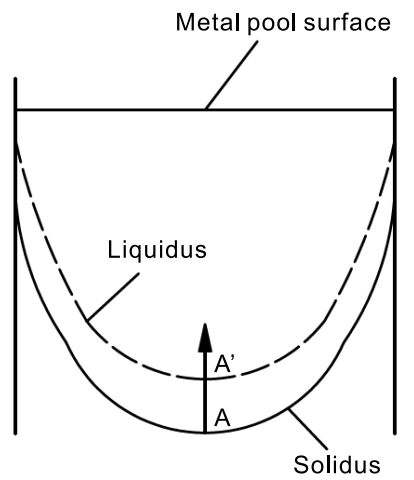

Fig. 12: Shape of metal pool

The local solidification time $(L S T)$ indicates the residence time of the alloy in the solid/liquid two-phase region, which is an important criterion for evaluating the solidification microstructure, and determines the primary and secondary dendrite spacing ${ }^{[14]}$

According to Flemings formula ${ }^{[15]}$, the relationship between $L S T$ and dendrite spacing $d$ is shown in Eq. (4):

$$
\log d=k_{1}+k_{2} \log L S T
$$

where $d$-dendrite spacing, $\mu \mathrm{m} ; k_{1}, k_{2}$-constant, decided by compositions of alloy. It can be seen from Eq. (4) that the shorter the $L S T$, the smaller the dendrite spacing, and thus, the better the solidification quality.

LST can be obtained using Eq. (5):

$$
L S T=\frac{X}{V}
$$

where $X$ is the distance between liquidus and solidus (mm) and $V$ is the local solidification rate $\left(\mathrm{mm} \cdot \mathrm{min}^{-1}\right)$.
As indicated by Fig. 12, with the increase of the remelting rate, the metal pool is deepened, and the distance $X$ between the liquidus and the solidus increases because the increase of the solidification rate is far less than that of the remelting speed ${ }^{[16]}$. According to Eq. (4), the LST increases, and the solidification quality of ESR ingot core gradually deteriorates with the increase of the remelting speed. This is also why many electroslag ingots often fail flaw detection at the ingot core.

When the remelting current is $1.5 \mathrm{kA}$, compared with the magnetic induction intensity is $0 \mathrm{Gs}$, the remelting speed increases by $35 \%$ when the magnetic induction intensity is $62 \mathrm{Gs}$, as shown in Fig. 10. As analyzed above, the increase of the remelting speed will make the metal pool deeper and aggravate the composition segregation. However, in this experiment, even if the remelting rate increases by $35 \%$, the segregation of carbon does not change much, and the phosphorus is slightly improved (Fig. 7). This shows that even if the melting rate increases, reasonable electromagnetic stirring can promote the redistribution of alloy elements and will not cause obvious segregation.

The above analysis shows that the large inclusions in the ESR ingot can be removed, and the solidification quality can be improved by applying reasonable electromagnetic stirring in the ESR process. However, excessive electromagnetic stirring force has adverse effects. For example, the intense electromagnetic stirring could cause violent convection heat transfer in the slag pool. The surface temperature of the slag pool would increase, raising the temperature of the consumable electrode above the slag surface due to the strong thermal radiation of the slag pool. Therefore, a stronger oxidation reaction would occur on the electrode surface, resulting in the increase of inclusions in the steel. In addition, if the electromagnetic force drives the metal droplet to move violently, the slag may be brought into the metal pool along with the molten metal droplet. At the same time, the movement of the slag pool and metal pool would also be stronger, which can entrap the slag into the metal pool ${ }^{[17]}$. The main feature of ESR slag is high fluorine content, but no fluorine is found in the inclusions in this experiment, which may be related to the detection technology. However, the involvement of slag 
cannot be completely excluded, and further research is needed in future. Similarly, excessive electromagnetic force may cause the solute enriched between dendrites to enter into the liquid phase, thus increasing the element segregation of the electroslag ingot ${ }^{[18]}$.

The electromagnetic stirring during the ESR process has a complex influence on the metallurgical quality of an ESR ingot. Especially, the unreasonable stirring parameters may deteriorate the metallurgical quality. Therefore, for different steel grades and ingots, the magnetic induction intensity must be carefully selected before using, and the effect of electromagnetic stirring must be comprehensively evaluated.

\section{Conclusions}

(1) With or without electromagnetic stirring, the types of inclusions in the ESR ingot remain basically unchanged, which mainly include $\mathrm{Al}_{2} \mathrm{O}_{3}, \mathrm{MnS}, \mathrm{MnS}$-oxide, and other oxides. When appropriate electromagnetic stirring with remelting current of $1.1 \mathrm{kA}$ and magnetic induction intensity of $62 \mathrm{Gs}$ is applied, the number of inclusions decreases significantly, the number of small inclusions increases, and the number of large inclusions decreases compared with an electroslag ingot without electromagnetic stirring.

(2) Electromagnetic stirring can affect the solidification process of an electroslag ingot and has different effects on the segregation of different elements. Under the experimental conditions, low electromagnetic force has little effect on the segregation of carbon, but has a better effect on the segregation of phosphorus.

(3) Excessive electromagnetic force will increase the number and diameter of inclusions and aggravate the segregation of alloy elements. The reason is that the electromagnetic force increases the stirring strength of the metal pool and slag pool, which can entrap the slag into the metal pool and cause the solute enriched between dendrites to enter into the liquid phase.

\section{Acknowledgements}

This work was financially supported by the National Natural Science Foundation of China (51774003/52074002/51974002) and the Ministry of Industry and Information Technology (TC190A4DA-35).

\section{References}

[1] Deng X X, Ji C X, Cui Y, et al. Formation and evolution of macro inclusions in IF steels during continuous casting. Ironmaking and Steelmaking, 2017, 44(10): 739-749.
[2] Li Z B. Electroslag metallurgy theory and practice. Beijing: Metallurgical Industry Press, 2010. (In Chinese)

[3] Zhou D G, Chen X C, Fu J, et al. Inclusions in electroslag remelting and continuous casting bearing steel. Journal of University of Science and Technology, 2000, 22(1): 26-30. (In Chinese)

[4] Shi X, Duan S T, Yang W S, et al. Effects of remelting current on structure, composition, microsegregation, and inclusions in Inconel 718 electroslag remelting ingots. Metallurgical and Materials Transactions B: Process Metallurgy and Materials Processing Science, 2019, 50(6): 3072-3087.

[5] Yang L, Cheng G G, Li S J, et al. Generation mechanism of TiN inclusion for GCr15SiMn during electroslag remelting process. ISIJ International, 2015, 55(9): 1901-1905.

[6] Murgaš M, Chaus A S, Pokusa A, et al. The electroslag remelting of high-speed steel using a magnetic field. ISIJ International, 2000, 40(10): 980-986.

[7] Mitchell A, Hernandez-Morales B. Electromagnetic stirring with alternating current during electroslag remelting. Metallurgical Transactions B: Process Metallurgy, 1990, 21(4): 723-731.

[8] Zhong Y B, Li Q, Fang Y P, et al. Effect of transverse static magnetic field on microstructure and properties of GCr15 bearing steel in electroslag continuous casting process. Materials Science \& Engineering A, 2016, 660(4): 118-126.

[9] Guo Y F, Xia Z B, Shen Z, et al. Effects of axial static magnetic field on inclusions removal in the liquid melt film during electroslag remelting process. Metallurgical and Materials Transactions B: Process Metallurgy and Materials Processing Science, 2021, 52(1): 282-291.

[10] Guo Y F, Xia Z B, Shen Z, et al. Enhancement of removing inclusions from liquid melt film during the ESR process assisted by a static magnetic field. Journal of Materials Processing Technology, 2021, 290: 116962.

[11] Li Q, Zhong Y B, Sun C X, et al. Effect of transverse static magnetic field on droplets transient and inclusions evolution during the electroslag remelting process of $\mathrm{GCr} 15$ ingots. Acta Metallurgica Sinica (English Letters), 2018, 31(12): 1311-1316.

[12] Wang H Z. Original position statistic distribution analysis (original position analysis) - A new analytical method in research and quality evaluation of materials. Science in China, Series B: Chemistry, 2003, 46(2): 119-123.

[13] Ren Z M, Lei Z S, Li C J, et al. New study and development on electromagnetic field technology in metallurgical processes. Acta Metallurgica Sinica, 2020, 56(4): 583-600. (In Chinese)

[14] Jiang Z H. Electroslag metallurgy. Beijing: Science Press, 2015. (In Chinese)

[15] Flemings M C. Solidification processing. Mcgraw-Hill, USA, 1974.

[16] Chang L Z, Li Z B. Numerical simulation of temperature fields in electroslag remelting slab ingots. Acta Metallurgica Sinica (English Letters), 2008, 21(4): 253-259.

[17] Shi X F, Chang L Z, Wang J J. Effect of mold rotation on the bifilar electroslag remelting process. International Journal of Minerals, Metallurgy and Materials, 2015, 22(10): 1033-1042.

[18] Wang P, Li S X, Zhang Z, et al. Effect of combined stirring modes on the solidification behavior of special steel bloom casting. Journal of Mechanical Engineering, 2020, 56(12): 99-106. 